\title{
COMENTARIO PROYECTO DE LEY USURPACIÓN DE AGUAS ${ }^{* * * *}$
}

\author{
COMMENTARY ON BILL OF WATER ENCROACHMENT \\ COMMENTAIRE SUR LE PROJET DE LOI D'USURPATION DE L'EAU \\ Jean Pierre Matus Acuña ${ }^{* * *}$
}

\section{INTRODUCCIÓN}

Se me ha conferido el honor de consultar mi opinión acerca del Proyecto de Ley en segundo trámite constitucional, que introduce modificaciones al marco normativo que rige las aguas en materia de fiscalización y sanciones (Boletín No 8149-09), remitiéndose para su análisis el Mensaje con que se dio comienzo a su tramitación y un texto comparado entre éste y el texto aprobado por la Honorable Cámara de Diputados.

Entiendo que la opinión que se me consulta tiene relación con mi especialidad, es decir, las materias de carácter penal que aborda el Proyecto, y que se encuentran en su artículo $2^{\circ}$, a saber, ciertas modificaciones a los artículos 459 y $460 \mathrm{del}$ Código Penal, que aumentan las penas previstas por la legislación actual en sus grados superiores y cuantía de las multas aplicables y agregan la mención expresa de las "aguas subterráneas" como objeto protegido penalmente. Para realizar este encargo, dividiré mi exposición en tres partes: primero, explicitaré los objetivos y propuestas del Proyecto; en segundo lugar, analizaré críticamente las posibilidades que existen de lograr los objetivos que se esperan alcanzar mediante dichas propuestas y, en tercer lugar, propondré modificaciones al Proyecto que tiendan a lograr los objetivos declarados del mismo.

\section{Objetivos y propuestas del Proyecto, en el Ámbito penal}

Las modificaciones propuestas, según el texto del Mensaje, tienen por objeto subsanar, en primer término, el déficit de "eficacia disuasiva" de que, según "la información recogida en fiscalizaciones efectuadas por la Dirección General de

\footnotetext{
*El presente análisis legislativo fue presentado como informe por el autor, al Presidente de la Comisión de Obras Públicas, del Senado de la República, honorable senador Sr. Jaime Quintana Leal, el $1^{\circ}$ de agosto de 2012.

** El artículo fue aprobado para su publicación el 20 de marzo de 2013.

*** Abogado. Licenciado en Derecho de la Pontificia Universidad Católica de Chile. Magíster y Doctor en Derecho por la Universidad Autónoma de Madrid, España. Profesor Titular de Derecho Penal de la Facultad de Derecho Universidad de Chile. Correo electrónico: jean.matus@gmail.com.
} 
Aguas", adolecerían las actuales penas previstas para el delito de usurpación de aguas, esto es, presidio menor en su grado mínimo y multa de once a veinte unidades tributarias mensuales, para el caso de usurpación no violenta (artículo 159 Código Penal), y la misma multa pero un presidio menor en su grado mínimo a medio, en caso de que la usurpación fuere violenta y las violencias no merecieren mayor pena. Se señala, además, que existiría un consenso político transversal en este aumento penológico, citándose mociones de senadores y diputados de diferentes bancadas y coaliciones Boletines $\mathrm{No}^{\circ}$. 6313-07 y 7522-07.

Para solucionar este "déficit disuasivo", se propone en el Mensaje elevar el grado máximo de las penas corporales de los artículos 159 y 160, proponiendo para el primero una pena de presidio menor en su grado mínimo a medio y para el segundo, de presidio menor en cualquiera de sus grados. En cuanto a las multas, se propone elevar su cuantía, en ambos casos, en el margen de veinte a quinientas unidades tributarias mensuales.

En segundo lugar, la mención expresa que se propone hacer de las aguas subterráneas en el texto del artículo 159 del Código Penal, pretendería subsanar las "dudas en cuanto a la aplicación de esta norma respecto de aquéllas", ello, a pesar de citarse en el texto del Mensaje el fallo del Tribunal Constitucional, el 13 de agosto de 2009 (STC Rol No 1281-2008), en que se admitió como una interpretación constitucionalmente admisible la de entender que la expresión "aguas" incluye tanto las superficiales como las subterráneas, sin infracción de la garantía de la tipicidad, atendido el sentido que la historia de la ley y los textos constitucionales le han otorgado a la expresión "aguas", en general.

El Mensaje añade la preocupación del Ejecutivo por la protección de las aguas subterráneas, cuya explotación "ha permitido el desarrollo de zonas agrícolas donde antes no era posible por la carencia total de aguas superficiales cercanas", considerando, "absolutamente esencial asegurar, más allá de toda duda, la plena aplicabilidad del tipo penal establecido en los artículos 459 y 460 del Código Penal”.

Por su parte, la H. Cámara de Diputados ha aprobado un texto que, en estos dos aspectos, hace suyo el razonamiento y las propuestas del Ejecutivo y va, por decirlo así, algo más allá, al elevar significativamente los montos de las multas cuya elevación se proponía originalmente hasta llegar al rango de veinte o cincuenta a cinco mil unidades tributarias mensuales, añadiendo, además, la "intimidación" como una forma de la figura agravada distinta de la "violencia" a que hace exclusiva referencia el texto actualmente vigente.

\section{Posibilidades de alcanzar los objetivos QUe Se PRETENDEN CON LAS PROpuestas del Proyecto aprobado por la \\ H. CÁmara de Diputados}

$\mathrm{Al}$ respecto, cumplo con informar a Ud. que los medios elegidos no permitirán alcanzar los fines propuestos, en atención a las razones que paso a exponer: 


\subsection{Imposibilidad de alcanzar un mayor efecto disuasivo con la sola elevación de los rangos superiores de las penas}

$\mathrm{Al}$ respecto, me permito señalar a Ud. que en la práctica jurisprudencial chilena, de conformidad con las reglas de determinación legal y judicial de la pena de los artículos 50 y siguientes del Código Penal y, particularmente, a partir de la entrada en vigencia de la Reforma Procesal Penal en todo el país, lo que determina la pena a imponer no es el grado máximo de ésta, sino el mínimo.

En efecto, el mínimo de la pena prevista por la ley es la sanción que, por regla general, se impone en casos de no concurrir atenuantes ni agravantes, pues aunque en tal caso existe la facultad de recorrer la pena en toda su extensión, los tribunales entienden que imponer grados superiores dentro del marco legal requeriría una justificación adicional. El mínimo es lo que se impone, también, obligatoriamente, en caso de concurrir una atenuante (por ejemplo: reparar con celo el mal causado, colaborar sustancialmente con el esclarecimiento de los hechos o tener una irreprochable conducta anterior). Sólo en el caso de la pena que se propone para la usurpación violenta (porque está compuesta de tres grados) el juez "no está obligado a imponer el máximo" en caso de concurrir una única atenuante, es decir, podría imponer el presidio menor en sus grados mínimo a medio. Pero si cuando no concurren circunstancias los jueces tienden al mínimo, es más bien claro que, por simple coherencia, el mínimo se impondrá de concurrir una atenuante. Y el mínimo en todos los casos es el mismo de la legislación actual: presidio menor en su grado mínimo, esto es, 61 a 540 días, es decir, en la práctica, 61 días.

Además, la consideración de una sola de estas atenuantes como "muy calificada" o la concurrencia de dos o más de ellas (p. ej., un caso en que concurra irreprochable conducta anterior y colaboración sustancial o reparación celosa del mal causado), permite reducir la pena en un grado o hasta en tres, a partir del mínimo, esto es, bajar la pena a 41 días (un grado), 21 días (2 grados) y hasta 1 día (tres grados).

Sólo en caso de concurrir agravantes y ninguna atenuante se podría, eventualmente, no imponer el mínimo o imponer la pena en su grado superior. Pero como a esta clase de delitos no se le aplican las agravantes especiales del artículo 456 bis, las posibles agravaciones quedan reducidas a la reincidencia.

Y aquí, el supuesto "efecto disuasivo" de las reformas propuestas choca con otra realidad: la del sistema procesal penal. En efecto, siendo tan bajo los mínimos, siempre es posible una salida negociada y, especialmente, la suspensión condicional del procedimiento, con la cual se permite al imputado no sufrir una condena a cambio de cumplir ciertas condiciones durante un tiempo no superior a tres años. En tales casos, que no requieren el acuerdo de la víctima, el imputado puede librarse de la condena y de quedar con antecedentes. Y puede hacerlo de manera ilimitada, es decir, tantas veces como convengan fiscales y defensores. Y, en caso de condena, como por regla general el imputado no tendrá antecedentes penales después de varias suspensiones condicionales, se puede optar por un procedimiento simplifi- 
cado o abreviado para ello, obteniendo el condenado alguno de los beneficios de la nueva Ley No 18.216, que le permitirán recibir hasta un total de alrededor de 5 condenas hasta sumar dos años de presidio remitidos o sustituidos por reclusión parcial, antes de que sea posible imponerle una pena corta de prisión, a estas alturas, incapaz de resocializarlo e inútil para la disuasión.

Como en un efecto dominó, y por no ser estos delitos crímenes, ahora ni en la propuesta que se debate, durante el proceso penal y tras la formalización correspondiente, los imputados gozarán de libertad, sin necesidad de rendir fianza ni otra garantía de comparecencia.

Quizás sólo la cuantía de las multas pudiera tener el efecto de que, al no pagarse, se le sustituya por prisión. Pero en este caso, la sustitución tendría un máximo de seis meses y equivaldría, según la regla de conversión del artículo 49 del Código Penal, a 36 UTM (1 UTM cada 5 días). Todo el exceso de multa impuesta sería "gratis". Y esto, sólo en el caso de que el imputado llegase efectivamente a ser condenado, lo cual, como hemos visto, se aleja mucho de las posibilidades reales que ofrece nuestro actual sistema penal para los simples delitos.

Finalmente, al no apuntar a los verdaderos beneficiarios de los hechos de mayor gravedad que se han conocido, esto es, las personas jurídicas en cuyo beneficio se realizan las usurpaciones de agua, se favorece el traspaso de las responsabilidades a las personas naturales y el disfrute por terceros de los beneficios de la comisión del delito.

\subsection{Efecto inesperado de agregar a la descripción legal actual la frase "aguas subterráneas"}

El artículo 19 No 3 de la Constitución y el artículo 18 del Código Penal establecen las reglas de la retroactividad favorable y la irretroactividad desfavorable del Derecho Penal. Según esta regulación, un nuevo delito no puede aplicarse retroactivamente y si se establece una nueva ley que beneficie al imputado o condenado, se ajustará a ella el juicio o la sentencia correspondiente.

Pues bien, al agregar expresamente las "aguas superficiales" al artículo 459 del Código Penal, se indica a los operadores que antes de esta modificación dichas aguas no se encontraban allí contempladas, pues de otra manera, tal modificación sería innecesaria.

Por lo tanto, desde la eventual entrada en vigencia de la ley así reformada, todos los procesos anteriores iniciados por usurpación de aguas subterráneas y todas las eventuales condiciones o condenas impuestas deberían arreglarse a la nueva ley, que declararía expresamente que antes de su vigencia la usurpación de tales aguas no se encontraba contemplada en el texto del Código Penal.

De este modo, el efecto inesperado de "eliminar las dudas de interpretación" por esta vía, sería aclarar que actualmente el artículo 459 del Código Penal no contempla el caso de usurpación de aguas superficiales, en contra de la intención 
del legislador y de la declaración del Tribunal Constitucional que sí lo admite. Ello, por cuanto las "dudas de interpretación” deben solucionarse por la vía técnica apropiada, esto es, una ley interpretativa en forma, y no por una modificación de los tipos penales.

Mutatis mutandi, lo mismo cabe decir del hecho de agregar la expresión "intimidación" a las "violencias", actualmente mencionadas en el artículo 260: en vez de aclarar una supuesta duda, provocará mayores dificultades interpretativas.

\section{Propuestas para alcanzar los objetivos esperados por medio de MODIFICACIONES LEGALES}

\subsection{Aumentando el efecto disuasivo de las penas actualmente previstas para el delito de usurpación de aguas}

De conformidad con lo dicho en el apartado anterior, hay sólo dos formas en nuestra legislación para aumentar el efecto disuasivo de las penas privativas de libertad: primero, subiendo el mínimo legal; y segundo, limitando tanto las salidas alternativas procesales como los beneficios de la Ley No 18.216. Si sólo se sube el mínimo (dentro de las penas de simples delitos), pero no se limitan estas salidas alternativas y esos beneficios, el efecto práctico de una reforma será tan irrelevante en términos disuasivos como la actualmente propuesta.

Por lo tanto, sugiero modificar el actual artículo $2^{\circ}$ propuesto para que el aumento de grados que se pretende se realice desde el mínimo y no desde el máximo de las penas actualmente previstas.

Por otra parte, el Proyecto mantiene el sistema concursal del artículo 460, que parece permitir imponer alternativamente las penas de este artículo o las de las violencias que se ejecutaren, si éstas fueren más graves. En ambos casos, las penas de un delito desplazarían a las del otro, quedando uno de ellos sin sanción, sistema que difiere del de la usurpación de bienes inmuebles, donde la ley expresamente ordena el castigo conjunto de tales hechos. Este sistema debe modificarse legislativamente, si se quiere mantener un castigo independiente por el delito de usurpación violenta.

Además, sugiero a Ud. se sirva plantear alguna limitación mínima a las posibilidades de salidas alternativas y de sustitución de las penas que, aun con la agravación arreglada en la forma que propongo, harán ilusoria su eficacia disuasiva, de emplearse en la forma que actualmente se emplean.

\subsection{Aclarando la incorporación de las "aguas subterráneas" en el actual texto del artículo 259 del Código Penal}

Como ya se dijo, para lograr el efecto de evitar las "dudas de interpretación" que el propio Tribunal Constitucional ya ha aclarado, lo que corresponde técnicamente es aprobar una disposición interpretativa que declare que la expresión 
"aguas" del artículo 259 del Código Penal comprende tanto las aguas superficiales como las subterráneas, tal como se encuentran definidas en el Código de Aguas vigente.

\subsection{Apuntando a los interesados y responsables: Disuadiendo a quienes reciben los beneficios}

En la actualidad, esta clase de delitos, atendida la escasez del recurso hídrico para distintas actividades mineras y agrícolas, su usurpación reporta importantes utilidades a quienes cometen o, más bien, hacen o dejan de cometer estos delitos, para beneficio de empresas organizadas jurídicamente. Por lo tanto, las medidas de prevención deben considerar extender la responsabilidad penal a las personas jurídicas que se benefician de esta clase de delitos.

\section{Conclusiones}

Por lo tanto, de conformidad con lo expuesto, sugiero a Ud. las siguientes indicaciones al Proyecto de Ley en discusión:

Para modificar el artículo $2^{\circ}$ propuesto, en el siguiente sentido:

“Artículo $2^{\circ}$. Introdúzcanse las siguientes modificaciones en el Código Penal:

1) Reemplácense en el encabezado del artículo 459 la expresión "mínimo" por "medio"; el guarismo "once" por "veinte", y el guarismo "veinte" por "cinco mil".

2) En el artículo 460:

i) Sustitúyase la frase "si el culpable no mereciere mayor pena por la violencia que causare", por "sin perjuicio de la pena que el culpable mereciere por las violencias que causare”.

ii) Reemplácese la frase "en sus grados mínimo a medio" por "en sus grados medio a máximo"; el guarismo "once" por "cincuenta", y el guarismo "veinte" por "cinco mil".

Para agregar un nuevo artículo $4^{\circ}$ :

“Artículo $4^{\circ}$. La suspensión condicional del procedimiento respecto de los imputados por alguno de los delitos previstos en los artículos 259 y 260 del Código Penal sólo procederá si entre las condiciones a imponer se considera el pago de una cantidad a beneficio fiscal no inferior a la multa que se impondría en caso de ser condenado, según lo previsto en el artículo 70 del Código Penal.

Tampoco procederá la suspensión condicional en caso de que el imputado tuviese procedimientos anteriores por esta misma clase de delitos, que hayan sido suspendidos condicionalmente, o en los cuales se le haya otorgado la oportunidad a que hace referencia el artículo 170 del Código Procesal Penal o hubiese sido condenado y sus penas sustituido por alguna de las previstas en la Ley No 18.216.

En los procesos por esta clase de delitos no se impondrán las penas sustitutivas de la Ley No 18.216 a quienes tuviesen dos o más procesos anteriores suspendidos 
o hubiesen sido condenados y sus penas sustituidas por alguna de las previstas en la Ley No 18.216 en dos o más procesos anteriores".

Para agregar un nuevo artículo $5^{\circ}$ :

“Artículo $5^{\circ}$. Se declara que la interpretación auténtica de la expresión 'aguas' del artículo 259 del Código Penal y de toda otra disposición que no haga distinción acerca de su naturaleza, comprende tanto las aguas superficiales como las subterráneas, de conformidad con lo dispuesto en el Código de Aguas".

Para agregar un nuevo artículo $6^{\circ}$ :

"Artículo $6^{\circ}$. Modifíquese el artículo $1^{\circ}$ de la Ley No 20.393, sustituyéndose la expresión 'y 251' por ', 251, 459 y 460”. 